\title{
Neurogenic orthostatic hypotension: the very basics
}

\author{
Horacio Kaufmann ${ }^{1} \cdot$ Jose-Alberto Palma ${ }^{1}$
}

Received: 7 June 2017/ Accepted: 8 June 2017/Published online: 15 June 2017

(c) The Author(s) 2017. This article is an open access publication

\section{Diagnosis}

The diagnosis of orthostatic hypotension $(\mathrm{OH})$ requires blood pressure (BP) readings while supine and upright, either during active standing or during a tilt-table test, to determine the presence of a sustained orthostatic fall of at least $20 \mathrm{mmHg}$ systolic or $10 \mathrm{mmHg}$ diastolic BP. BP and heart rate should be measured after the patient has been supine for several minutes and after standing still (or passively tilted) for 1-3 min. The changes in heart rate on standing help to determine whether the $\mathrm{OH}$ is neurogenic in origin. In patients with neurogenic $\mathrm{OH}(\mathrm{nOH})$ the increase in heart rate upon standing up is usually $<20 \mathrm{bpm}$. Marked increases in heart rate suggest that the $\mathrm{OH}$ is non-neurogenic (Table 1).

\section{Symptomatic or asymptomatic}

Patients with nOH may or may not have symptoms. Symptoms of nOH typically disappear after the patient resumes the sitting or lying position because cerebral blood flow is restored to levels above the lower limit of

Horacio Kaufmann

Horacio.Kaufmann@nyumc.org

1 Department of Neurology, Dysautonomia Center, New York University School of Medicine, 530 First Avenue, Suite 9Q, New York, NY 10017, USA autoregulatory capacity (Fig. 1). The chronic nature of nOH allows remarkable adaptive changes in cerebral autoregulatory mechanisms. Indeed, patients with $\mathrm{nOH}$ are frequently able to tolerate wide swings in BPs and often remain conscious at pressures that would otherwise induce syncope in healthy subjects $[2,5]$.

\section{Ambulatory blood pressure monitoring}

Ambulatory blood pressure monitoring (ABPM) is useful for the diagnosis of $\mathrm{nOH}$ in patients who do not have a fall in BP during an office visit, and to identify postprandial hypotension and nocturnal hypertension [3] (Fig. 2).

\section{Management}

The goal of treatment is not to normalize standing BP, but to reduce symptom burden, and to improve quality of life. The steps in management include: (1) correcting aggravating factors, (2) implementing non-pharmacological measures, and (3) drug therapies (Fig. 3).

\section{Non-pharmacologic management}

Non-pharmacologic management is vital and often underestimated to ameliorate the symptoms and severity of neurogenic orthostatic hypotenion $(\mathrm{nOH})$. Patients and their families or caregivers should understand the basics of nOH pathophysiology and the importance of nonpharmacologic methods. In many situations, educational materials may be helpful for both the patient and the 
Table 1 Characteristics of neurogenic and non-neurogenic orthostatic hypotension Modified from [4]

\begin{tabular}{|c|c|c|}
\hline & Non-neurogenic orthostatic hypotension & Neurogenic orthostatic hypotension \\
\hline Frequency & Frequent (particularly in the elderly) & Rare $(<200,000$ in the US $)$ \\
\hline Onset & Variable & $\begin{array}{l}\text { Chronic in synucleinopathies. Acute or sub-acute } \\
\text { in immune-mediated neuropathies and } \\
\text { ganglionopathies }\end{array}$ \\
\hline Causes & $\begin{array}{l}\text { Intravascular volume loss (e.g., dehydration, } \\
\text { anemia) } \\
\text { Antihypertensive medications } \\
\text { Blood pooling (e.g., large varicose veins, skeletal } \\
\text { muscle atrophy) } \\
\text { Physical deconditioning, Advanced heart failure } \\
\text { Adrenal insufficiency }\end{array}$ & $\begin{array}{l}\text { Defective norepinephrine release from } \\
\text { sympathetic post-ganglionic neurons upon } \\
\text { standing up }\end{array}$ \\
\hline Prognosis & Resolves when underlying cause is corrected & Chronic disorder \\
\hline Increase in heart rate upon standing & Pronounced (usually >25 bpm) & Mild or absent (usually $<20$ bpm) \\
\hline $\begin{array}{l}\text { Blood pressure overshoot } \\
\text { (phase 4) in Valsalva maneuver }\end{array}$ & Present & Absent \\
\hline $\begin{array}{l}\text { Increase in plasma norepinephrine } \\
\text { levels upon standing }\end{array}$ & Normal or enhanced (at least $\times 2$ ) & Reduced or absent (less than $\times 2$ ) \\
\hline Other symptoms of autonomic failure & No & $\begin{array}{l}\text { Constipation } \\
\text { Erectile dysfunction (men) } \\
\text { Urinary abnormalities } \\
\text { Sweating abnormalities }\end{array}$ \\
\hline Concomitant neurological deficits & None (or if present, they are not related to $\mathrm{OH}$ ) & $\begin{array}{l}\text { None } \\
\text { Parkinsonism } \\
\text { Cerebellar signs } \\
\text { Cognitive impairment } \\
\text { Sensory neuropathy }\end{array}$ \\
\hline
\end{tabular}

caregiver (Table 2). Physical inactivity and prolonged bed rest are common in patients with $\mathrm{nOH}$. This leads to cardiovascular deconditioning further worsening the fall in BP and increasing symptoms leading to a vicious cycle (Fig. 4).

\section{Pharmacologic treatments}

The selection of one drug over the other is related not only to the severity of the patient's symptoms, but also, in certain situations, based on the clinician's preference and experience with a certain drug (Table 3 ).

\section{Treatment of supine hypertension associated with neurogenic orthostatic hypotension}

Hypertension in the supine occurs in $\sim 50 \%$ of patients with $\mathrm{nOH}$. There are no controlled clinical trials on its treatments. In patients with $\mathrm{nOH}$ experiencing supine hypertension [systolic blood pressure (BP) of 160-180 mmHg or diastolic $\mathrm{BP}$ of 90-100 $\mathrm{mmHg}$ ], there is agreement that sleeping with the head of the bed raised at least $30^{\circ}-45^{\circ}$ should be recommended. If patients are experiencing sustained severe supine hypertension (systolic BP of $>180 \mathrm{mmHg}$ or diastolic BP of $>110 \mathrm{mmHg}$ ) even after sleeping in the semi-sitting position, some experts advocate using short-acting an anti- 

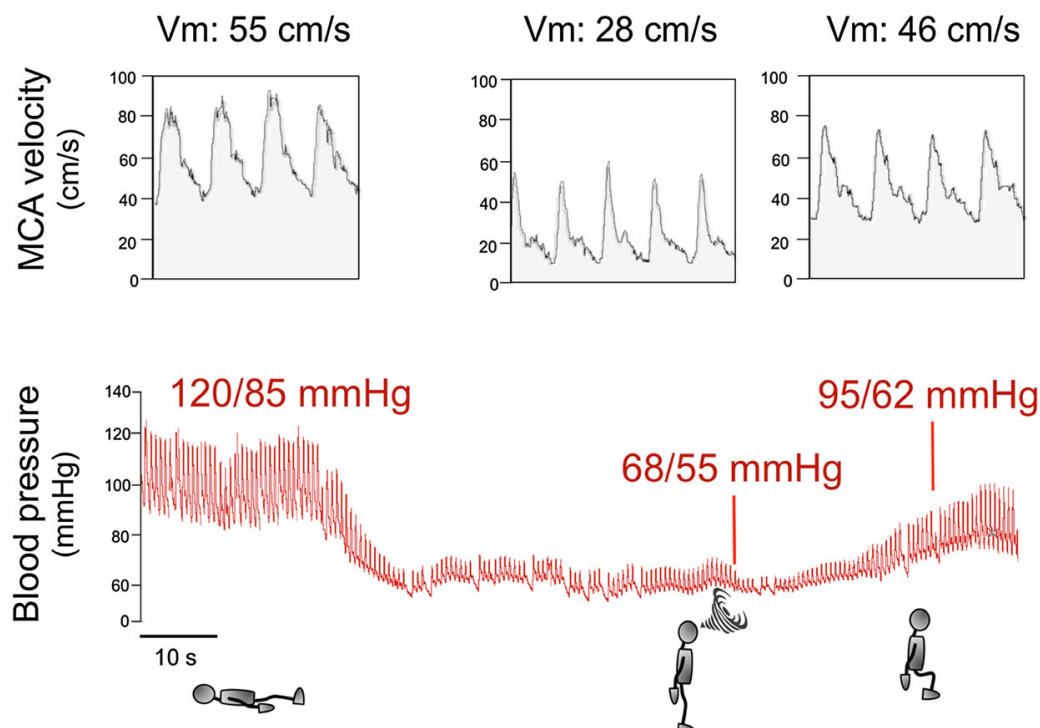

Fig. 1 Blood pressure and cerebral blood flow in a patient with neurogenic orthostatic hypotension [4]. The upper tracing displays blood flow velocity as measured by transcranial Doppler ultrasound of the middle cerebral artery (MCA), which is proportional to cerebral blood flow. The lower tracing shows continuous blood pressure recorded with plethysmography. When the patient is in the supine position, BP is normal $(120 / 85 \mathrm{mmHg})$ and MCA velocity $(\mathrm{Vm})$ is $55 \mathrm{~cm} / \mathrm{s}$, indicating normal cerebral blood flow. When the patient stands up, BP drops rapidly to $68 / 55 \mathrm{mmHg}$ and cerebral blood flow

falls by nearly $50 \%$ as shown by $\mathrm{Vm}$ down to $28 \mathrm{~cm} / \mathrm{s}$. The patient becomes symptomatic, feels faint and is unable to remain standing (indicated by a swirl). The patient then sits down and his BP increases to $95 / 62 \mathrm{mmHg}$. Although this BP value is still low, the patient is not symptomatic because $\mathrm{Vm}$ increased to $46 \mathrm{~cm} / \mathrm{s}$, indicating almost normal cerebral blood flow. This tracing shows that for a patient to become asymptomatic, BP does not have to return to normal values but only to increase above the lower limit of cerebral autoregulation

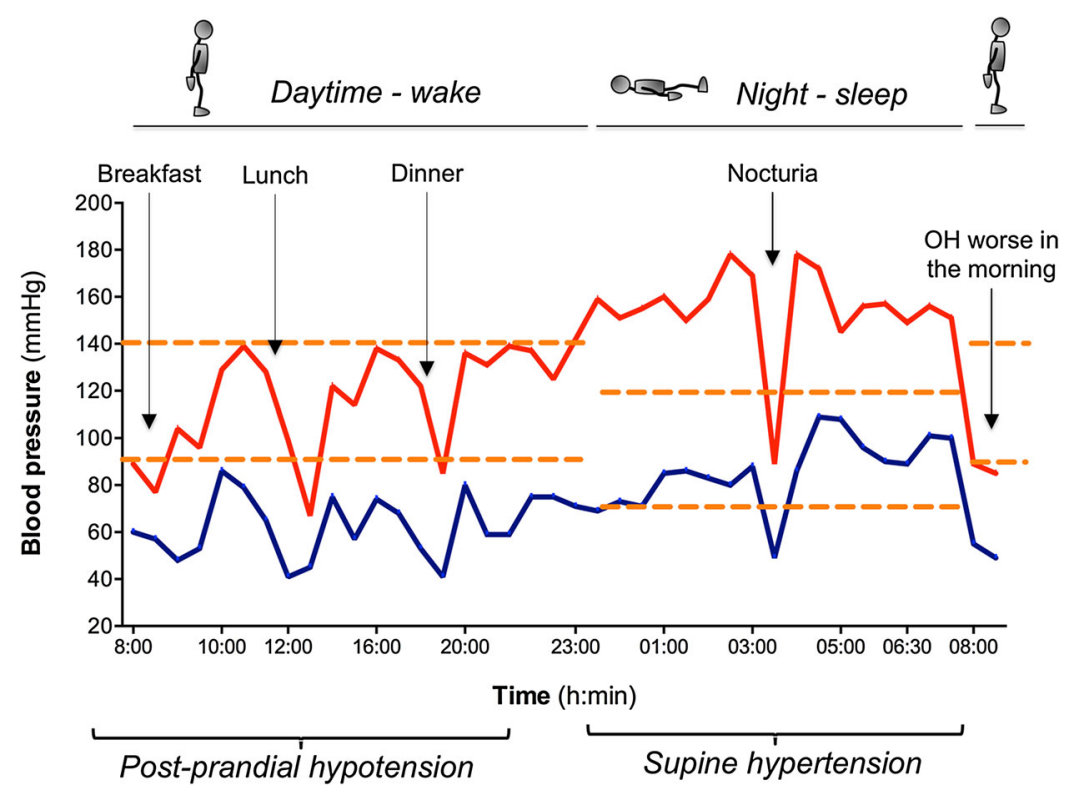

Fig. 2 Typical 24-h ambulatory blood pressure (BP) monitoring results in a patient with neurogenic $\mathrm{OH}$ and supine hypertension. The orange dashed horizontal red denotes the limit for hyper- or hypotension. There is a significant drop in BP (systolic BP $<90 \mathrm{mmHg}$ ) after breakfast, lunch and dinner (arrows). According to this patient's diary, lunch consisted of a slice of cheese pizza with French fries and a piece of cheesecake, all accompanied by a glass of wine. This is consistent with postprandial hypotension. The patient

also had nocturnal hypertension (up to systolic BP of $180 \mathrm{mmHg}$ ) while sleeping in the supine position, and one episode of hypotension (while he was in the standing position in the bathroom urinating). Upon awakening the next morning, his orthostatic hypotension is worse due to volume depletion overnight. This recording emphasizes the need to sleep with the head of the bed raised $30^{\circ}-45^{\circ}$ and to avoid high-calorie meals and alcohol during daytime 


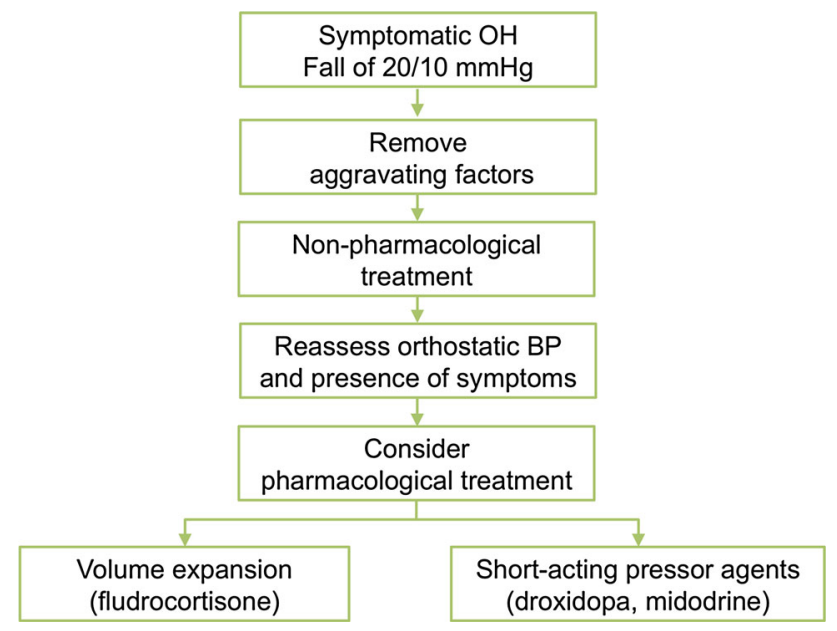

Fig. 3 Treatment algorithm in patients with neurogenic orthostatic hypotension. Modified from [4]. Removal of aggravating factors and initiation of non-pharmacological measures must always predate pharmacological agents

hypertensive agent before bedtime (Table 4). This remains controversial and clinicians must be aware that pharmacological treatment for supine hypertension increases the risk of worsening hypotension and falls when the patient gets up at night or in the early morning.

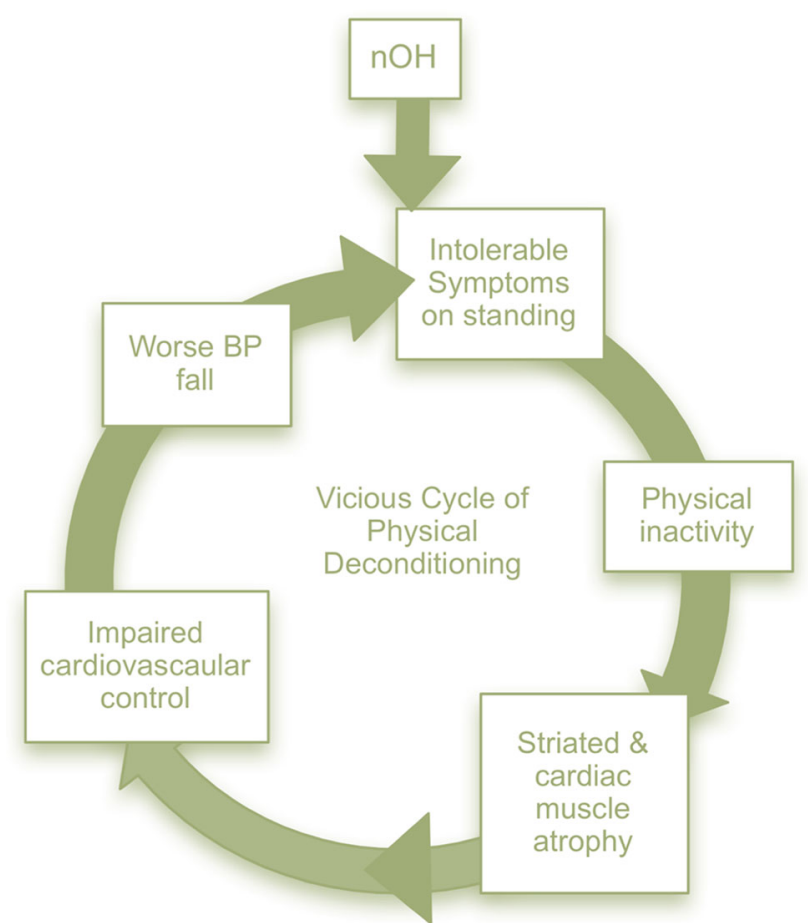

Fig. 4 The vicious cycle of physical deconditioning. Modified from [4]. Because patients with neurogenic orthostatic hypotension (nOH) have intolerable symptoms when standing they avoid moving; lack of physical activity results in striated and cardiac muscle atrophy, which further impairs cardiovascular control. This, in turn, further increases the orthostatic fall in blood pressure, worsening symptoms in a perpetual cycle. Improving symptoms can break this cycle

Table 2 Recommendations of non-pharmacologic treatments for neurogenic orthostatic hypotension Reproduced from [1]

\begin{tabular}{|c|c|}
\hline Treatment & Notes \\
\hline $\begin{array}{l}\text { Educate patients and their } \\
\text { caregivers }\end{array}$ & $\begin{array}{l}\text { Includes education on understanding orthostatic intolerance; avoiding prolonged standing, immobilization, or } \\
\text { prolonged diurnal recumbence; as well as rising gradually from supine and sitting positions, especially in the } \\
\text { morning, after meals, and after urination/defecation }\end{array}$ \\
\hline Change diet & $\begin{array}{l}\text { Eat smaller, rather than large, and more frequent meals. With nOH, sympathetic vasoconstrictor nerve activity } \\
\text { is deficient and many patients become severely hypotensive within } 2 \mathrm{~h} \text { of eating. In patients with postprandial } \\
\text { hypotension, smaller and more frequent meals are recommended }\end{array}$ \\
\hline $\begin{array}{l}\text { Avoid increased core body } \\
\text { temperature }\end{array}$ & $\begin{array}{l}\text { Elevation in body temperature causes peripheral vasodilation. Patients with nOH should avoid situations that } \\
\text { could increase core body temperature, such as excessive high-intensity exercise; exercise when ambient } \\
\text { temperature and humidity are high; utilization of hot-tubs, spas, or saunas; prolonged hot showers, etc. }\end{array}$ \\
\hline $\begin{array}{l}\text { Avoidance of physical } \\
\text { deconditioning }\end{array}$ & $\begin{array}{l}\text { Lower body strength training and moderate, non-strenuous activities may be incorporated into standard } \\
\text { treatment for patients with nOH }\end{array}$ \\
\hline $\begin{array}{l}\text { Use head-up position while } \\
\text { sleeping }\end{array}$ & $\begin{array}{l}\text { Use of head of the bed elevation up to } 30 \text { degrees during sleep. This may reduce nocturia, volume depletion, } \\
\text { and supine hypertension }\end{array}$ \\
\hline Increase hydration & $\begin{array}{l}\text { Increased fluid intake, including rapid water bolus intake if needed, can potentially combat acute nOH } \\
\text { symptoms. Volume expansion requires up to } 64 \mathrm{oz} \text { of water daily. Proper hydration can produce both acute } \\
\text { and long-lasting significant clinical benefits to patients with nOH }\end{array}$ \\
\hline Increase salt intake & $\begin{array}{l}\text { For the patient with } \mathrm{nOH} \text {, it is recommended that they add up to } 1-2 \text { teaspoons }(2.3-4.6 \mathrm{~g}) \text { of salt per day to } \\
\text { their normal diet. However, increasing salt intake should be used with caution in patients with heart and } \\
\text { kidney failure }\end{array}$ \\
\hline Use compression garments & $\begin{array}{l}\text { These provide a reduction of peripheral pooling in the lower limbs and splanchnic region. Compression of } \\
30-40 \mathrm{mmHg} \text { is required to improve venous return and provide a meaningful blood pressure impact. } \\
\text { Abdominal binders offer an effective alternative }\end{array}$ \\
\hline $\begin{array}{l}\text { Treat anemia and vitamin } \\
\text { deficiencies }\end{array}$ & $\begin{array}{l}\text { Anemia leads to decreased blood viscosity and oxygen-carrying capacity and may worsen symptoms of } \mathrm{nOH} \text {. } \\
\text { Vitamin } \mathrm{B} 12 \text { deficiency }(<250 \mathrm{pg} / \mathrm{mL} \text { with elevated methylmalonic acid levels }) \text { may also unmask or } \\
\text { exacerbate symptoms of } \mathrm{nOH}\end{array}$ \\
\hline
\end{tabular}


Table 3 Pharmacologic treatments for neurogenic orthostatic hypotension Modified from [1]

\begin{tabular}{|c|c|c|c|}
\hline Treatment & Recommended dosing regimen & Drug class and notes & Safety notes \\
\hline \multicolumn{4}{|c|}{ FDA-approved for the treatment of symptomatic neurogenic $\mathrm{OH}$} \\
\hline Droxidopa & $\begin{array}{l}\text { 100-600 mg three times/day (dosed } \\
\text { morning, midday, and } 3-4 \mathrm{~h} \text { prior } \\
\text { to bedtime) or tailored to each } \\
\text { patients' needs }\end{array}$ & Pro-drug of norepinephrine & $\begin{array}{l}\text { Supine hypertension, headache, dizziness, } \\
\text { nausea, and fatigue; caution in } \\
\text { congestive heart failure and chronic } \\
\text { renal failure }\end{array}$ \\
\hline Midodrine & $\begin{array}{l}2.5-15 \mathrm{mg} \text { twice or three times/day } \\
\text { (dosed morning, midday, and } 3-4 \mathrm{~h} \\
\text { prior to bedtime) }\end{array}$ & Direct alpha1-adrenoreceptor agonist & $\begin{array}{l}\text { Supine hypertension, piloerection, scalp } \\
\text { itching, and urinary retention; caution in } \\
\text { congestive heart failure and chronic } \\
\text { renal failure }\end{array}$ \\
\hline \multicolumn{4}{|c|}{ Not specifically FDA-approved for neurogenic $\mathrm{OH}$} \\
\hline Fludrocortisone & $\begin{array}{l}0.1-0.2 \mathrm{mg} / \text { day; little benefit from } \\
\text { observed dose beyond } 0.2 \mathrm{mg} / \mathrm{day}\end{array}$ & $\begin{array}{l}\text { Synthetic mineralocorticoid. } \\
\text { Fludrocortisone is a volume expander } \\
\text { that increases sodium reabsorption } \\
\text { and enhances sensitivity of alpha- } \\
\text { adrenoreceptors }\end{array}$ & $\begin{array}{l}\text { Supine hypertension, hypokalemia, renal } \\
\text { failure, and edema; caution in } \\
\text { congestive heart failure }\end{array}$ \\
\hline Pyridostigmine & $30-60 \mathrm{mg}$ twice or three times/day & $\begin{array}{l}\text { Acetylcholinesterase inhibitor. } \\
\text { Marginal efficacy in nOH }\end{array}$ & $\begin{array}{l}\text { Abdominal cramps, diarrhea, sialorrhea, } \\
\text { excessive sweating, urinary } \\
\text { incontinence }\end{array}$ \\
\hline
\end{tabular}

Table 4 Pharmacological treatments for supine hypertension associated with neurogenic orthostatic hypotension Modified from [1]

\begin{tabular}{ll}
\hline Treatment options $^{\mathrm{a}}$ & Typical dose \\
\hline Captopril & $25 \mathrm{mg}$ at bedtime \\
Clonidine $^{\mathrm{b}}$ & $0.1 \mathrm{mg}$ with dinner \\
Hydralazine & $10-25 \mathrm{mg}$ at bedtime \\
Losartan & $50 \mathrm{mg}$ at bedtime \\
Nitroglycerine patch & $0.1 \mathrm{mg} / \mathrm{h}$ patch at bedtime (remove patch in the morning) \\
\hline
\end{tabular}

No controlled trials have been performed. The risk-benefit ratio should be individually assessed

a Short-acting antihypertensives should be administered at bedtime only, not during daytime hours. Many medications have twice or three times/day as recommended dosing and patients may inadvertently start taking these medications during daytime hours and worsen symptoms of $\mathrm{nOH}$

b The use of clonidine carries a risk of a severe hypotension in the morning as well as rebound hypertension

\section{Compliance with ethical standards}

Funding This manuscript is part of a supplement sponsored by Lundbeck.

Conflict of interest Dr. Kaufmann serves as a member of Advisory Board for Lundbeck and is Editor-in-Chief of Clinical Autonomic Research. Dr. Palma serves as a member of the Advisory Board for Lundbeck and is Managing Editor of Clinical Autonomic Research.

Open Access This article is distributed under the terms of the Creative Commons Attribution 4.0 International License (http://crea tivecommons.org/licenses/by/4.0/), which permits unrestricted use, distribution, and reproduction in any medium, provided you give appropriate credit to the original author(s) and the source, provide a link to the Creative Commons license, and indicate if changes were made.

\section{References}

1. Gibbons CH, Schmidt P, Biaggioni I, Frazier-Mills C, Freeman R, Isaacson S, Karabin B, Kuritzky L, Lew M, Low P, Mehdirad A,
Raj SR, Vernino S, Kaufmann H (2017) The recommendations of a consensus panel for the screening, diagnosis, and treatment of neurogenic orthostatic hypotension and associated supine hypertension. J Neurol 1-6. doi: 10.1007/s00415-016-8375-x

2. Horowitz DR, Kaufmann H (2001) Autoregulatory cerebral vasodilation occurs during orthostatic hypotension in patients with primary autonomic failure. Clin Auton Res 11:363-367

3. Norcliffe-Kaufmann L, Kaufmann H (2014) Is ambulatory blood pressure monitoring useful in patients with chronic autonomic failure? Clin Auton Res 24:189-192

4. Palma JA, Kaufmann H (2017) Epidemiology, diagnosis, and management of neurogenic orthostatic hypotension. Mov Disord Clin Pract. doi: $10.1002 / \mathrm{mdc} 3.12478$

5. Palma JA, Gomez-Esteban JC, Norcliffe-Kaufmann L, Martinez J, Tijero B, Berganzo K, Kaufmann H (2015) Orthostatic hypotension in Parkinson disease: how much you fall or how low you go? Mov Disord 30:639-645 